\title{
TV Series Subtitle Translation Based on Skopos Theory
}

\author{
CHEN Xiao-hui, WANG Gui-lian \\ University of Shanghai for Science and Technology, Shanghai, China
}

\begin{abstract}
Subtitle translation has ever been dominated by the principles of "faithfulness" and "equivalence", and neither of them can convey the meaning of the original film dialogues very well. The main principle of Skopos Theory lays stress on the fact that result determines the whole translation behavior, making the target spectators understanding the dialogue the main goal of TV series subtitle translation. Taking Friends as an example, this paper conducts a study on the better ways of subtitle translation based on Skopos Theory.
\end{abstract}

Keywords: subtitle translation, Skopos Theory, translation strategies

\section{Introduction}

As foreign films and TV series are gradually becoming part of people’s lives, great importance has been attached to film translation both abroad and at home.

In 1974, Dollerup published his article named “On Subtitles in Television Programs”, marking the beginning of subtitle translation study. In 1993, Gottlieb analyzed the theoretical basis of subtitling in his book Subtitling: A New University Discipline, and put forward the ideas that "Subtitling can be either intralingual or vertical, when the target language is the same as the source language, and interlingual or diagonal, when the target language is different from the source language” (Gottlieb, 1994). In China, Zhang Chunbai who serves as a pioneer in subtitle translation study summarizes the features of audiovisual forms of literature in a brief way. Ma Zhengqi, whose key research includes translation and cross-cultural communication, analyzes principles of film translation from five representatives: "be colloquial language; be in accordance with character's personality; satisfy the emotional needs of the film; achieve lip-synchronization and be popular language” (Ma, 2000). In 2005, Ma published another book named Scenario Translation \& Dubbing in which he explores in depth the nature, characteristics, and significance of subtitle translation.

From the above, it can be seen that most of previous researches mainly center on the theoretical analysis of subtitle translation and seldom emphasize on the methods of subtitle translation. Therefore, this paper tries to explore the translation strategies of subtitle translation from the perspective of Skopos Theory.

\section{General Introduction to Skopos Theory}

Skopos Theory, proposed by German translation theorist—Hans Vermeer, consists of three main guiding rules: Skopos Rule, the Coherence Rule, and the Fidelity Rule.

Skopos Rule, which means "purpose principle", holds the ideas that the purpose of translation behavior determines the whole process of translation behavior, i.e., the method of result determination. So the translator

CHEN Xiao-hui, Master, Foreign Language College, University of Shanghai for Science and Technology, Shanghai, China.

WANG Gui-lian, Master, Associate Professor, Foreign Language College, University of Shanghai for Science and Technology, Shanghai, China. 
should define his or her specific purpose in a given translation context and decide what translation strategies and methods to adopt according to this purpose.

Coherence Rule: The principle of coherence means that the translator should create a text acceptable to the target reader, that is, the translation should be readable and acceptable to achieve intra-textual coherence (Zhang \& Wang, 2005, p. 41), that is, the target text must be translated in the coherence of the recipient of the target text because both of their circumstances and knowledge are the same (Mundy, 2001).

Fidelity Rule means "the principle of faithfulness", that is, there should be inter-textual coherence between the original text and the target text, but the degree and form of faithfulness with the original text depend on the purpose of the target text and the translator's understanding of the original text.

The status of these three principles is unequal; the Skopos principle is above the other two principles; and the principle of Fidelity is subordinated to the principle of coherence. In the following part, the author will apply the Skopos Theory to the subtitle translation analysis under the guidance of the three principles.

\section{Analysis of Subtitle Translation}

Skopos Theory gives high priority to its core content that the overall translation behaviors are subjected to the main factors contained in the translation. Concerning the process of subtitle translation, the main purpose is to enable the target audience to understand the meaning of dialogue in the film through the translation of subtitles. Because of cultural differences, dialogues in foreign films involve many cultural factors that the target audience does not understand which results in the difficulty to understand the sense of humor contained in the lines. Therefore, when it comes to translate subtitles, the translator should focus on the target audience and translate the subtitles into an acceptable and comprehensible mode for the target audience. Next, taking the subtitle translation in Friends as an example, this paper will expound this point in detail.

\section{Translation of Culture-Loaded Words}

According to the Skopos Rule, the purpose of translation is to help the target audience to understand the original text. However, due to the cultural differences, it is necessary to take full consideration of the psychological feelings of the targeted spectators; thus, some culture-loaded words have to be involved to transfer the actual meanings in the translation.

Example 1

Chandler: "Well, Joey, I wrote a little song today. It’s called: Get Up."

Joey: "All right! You can have the chair."

Chandler: "Really!”

Joey: "All right, me would you look at that! (holds up crossed fingers).”

钱德勒: “乔伊, 我今天写了首歌, 名字叫《起来》”。

乔伊: “好吧, 椅子归你了。”

钱德勒: “真的吗?”

乔伊：“天啊，你没看我这个手势吗？（此手势表示说话者在说谎。）”

In translating these sentences, the translator should let the audience understand what Joey means by crossing his fingers. In American culture, there are some unique gestures, such as "quotation marks" and "crossed fingers" etc. They all have a certain meaning, which is difficult for the Chinese audience to understand. "Crossed fingers", by crossing index fingers and middle fingers, means that the person making the gesture is 
lying. In the above lines, by raising his prayer finger, Joey means that he's not serious about what he says. However, the Chinese audience will not understand the gesture, so in the subtitle translation, in line with the principle of purpose, the translator should add some words to explain Joey's implied meaning to achieve the purpose of making the audience understand this point.

Example 2

Rachel: I'm sorry. I didn’t-I don’t come in here a lot.”

Mr. Trigger: "Oh yeah, of course you don't!”

Rachel: "NO."

Mr. Trigger: "Because you're a little princess! Daddy, buy me a pizza. Daddy, buy me a candy factory. Daddy, make the cast of Cats sing Happy Birthday to m...”

瑞秋: 真对不起! 我不是经常来这。

Trigger: 是啊, 你当然不常来这。

瑞秋: 对。

Trigger: 因为你是个小公主 “爸爸, 我要买份披萨, 爸爸, 我要买个糖果厂, 让《猫》剧 的演员们为我唱生日歌”。

In the last sentence, “make the cast of Cats sing Happy Birthday to m...” should be translated into “让 《猫》 剧的演员们为我唱生日歌” rather than “让猫咪们为我唱生日歌”. If you translate this sentence into letting cats singing birthday song for me, the audience may not understand why a group of cats should be asked to sing birthday songs. In Broadway musical cats, kittens sing Happy Birthday to celebrities. So translators should consider the original cultural image and translate Cats into “《猫》剧的演员们”. In this way, the audience will understand the cultural factors involved in the play and achieve the understanding of the dialogue of the original play, which is in line with the principle of Skopos Rule.

Example 3

Rachel: "Does it?"

Ross: "It does."

Ross: "It so does not!"

瑞秋: “可以么?”

罗斯: “行。”

罗斯： “行你个头!”

Because of the differences in cultures, the ways of expressing emotions are also different between China and foreign countries; therefore, different translation methods should be adopted to make the audience understand the emotional effect of the original dialogue. If the sentence "It so does not!" is translated into “才 不行呢”, the dialogue will not only lose its emotional effect but also cannot be fully understood by the target viewers with different cultural backgrounds. But if the Chinese version is “行你个头”, the audience can better understand the inner emotion of Ross's dissatisfaction.

\section{Acceptability of the Target Audience}

According to the principle of coherence, we should pay attention to the acceptability and readability of the translation subtitles. The acceptability of the translated language means that the translated language conforms to the language habits of the target language reader and has intra-textual coherence.

Example 4 
Rachel: $\quad$ Can you believe what a jerk Ross was being?

Monica: $\quad$ Yeah, I know. He can get really competitive.

Phoebe: Ha. Ha, Ha.

Monica: What?

Phoebe: $\quad$ Oh, hello, kettle? This is Monica. You're black.

瑞秋: 你知道罗斯这个混蛋有多烂吗?

莫妮卡: 我知道, 他好胜心很强。

菲比: 哈、哈、哈。

莫妮卡: 什么?

菲比: 真是五十步笑百步!

If the sentence “Oh, hello, kettle? This is Monica. If you're black" is translated literally, it would be “凯 蒂, 我是摩妮卡, 你是黑人”. In this way, the Chinese audience will find it hard to understand what Phoebe is going to say, thus reduce the audience's interest in the play. According to the coherence principle, when translating subtitles, translators should fully consider the readers' language habits and language acceptance ability, and employ an acceptable version to understand the source language. Therefore, if the underlined sentence is translated into “五十步笑百步”, it is not only easy to understand, but also in line with the expectations of the Chinese audience.

Example 5

Phoebe: $\quad$ You can turn around, or you can go rip the Band-And off.

Rachel: $\quad$ OK, let's rip.

菲比: 你可以转身离开, 或者长痛不如短痛

瑞秋: 好吧, 那就短痛吧

In this conversation, "go rip the band-aid off" originally means "to uncover the sticker at once, although it hurts, but it passes all at once". This sentence implies that doing something will cause bad effect, but it is better to deal with it as quickly as possible to avoid long pain. If you literally translate "you can go rip the band-aid off” into “你可以转身离开, 直接把创口贴撕下来”, the audience will be confused by Phoebe's words. But if the translated version is “长痛不如短痛”, Chinese audiences will understand and accept it more easily, because this is a quite popular Chinese expression.

\section{Conclusion}

Making the spectators fully understand the dialogues in the film or television shows is the highest goal of subtitle translation. Skopos Theory gives high priority to its core content that the overall translation behaviors are subjected to the purposes and the target audience. This paper makes a study on the translation strategies of TV series subtitle translation, especially the ways of conveying the specific emotions or implied meanings contained in the film or TV dialogues. In so doing, the target audience can better appreciate the foreign films or TV series, thus understand the culture differences in different countries.

\section{References}

Gottlieb, H. (1994). Subtitling: Diagonal translation. Amsterdam: John Benjamins Publishing Company Press. Mundy, J. (2001). Introducing translation studies-theories and applications. London and New York: Routledge. Ma, Z. Q. (2000). An introduction to film and television translation system. Beijing: Communication University of China Press. Zhang, M. F., \& Wang, K. F. (2005). Functional translation theory. Beijing: Foreign Language Teaching and Press. 